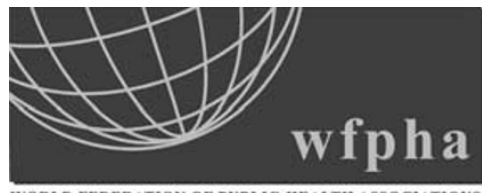

\title{
WFPHA: World Federation of Public Health Associations
}

www.wfpha.org

Journal of Public Health Policy (2007) 28, 363-375.

doi:10.1057/palgrave.jphp.3200144

\section{THE FEDERATION'S PAGES}

Editorial: APHA and WFPHA Work for Global Public Health Vision

In May, the American Public Health Association (APHA) participated in a retreat in Bellagio, Italy, to update the strategic plan for the World Federation of Public Health Associations (WFPHA), an organization of over 70 national and regional public health associations founded in 1967. The new plan for 2007-2012 has ambitious goals:

- to strengthen and sustain the WFPHA infrastructure, currently housed at the APHA office in Washington,

- to be the leader for a global exchange on practice, education/training, and research in global public health, and

- to develop and implement policies to improve the health of populations.

Because member country associations vary in many ways - membership structures; inclusion of particular disciplines; and emphasis (on research, practice, and/or training) - it was important to assure that WFPHA's vision and mission be based on a broad public health approach using a social determinants model of health. WFPHA promotes health as a fundamental right and public good. It supports values of social justice, diversity and inclusion, partnership, and ethical conduct.

In the United States, we need local public health affiliates to be strong advocates for public health, to facilitate networking among

- Hournal of Public Health Policy 2007, 28, 363-375 (C 2007 Palgrave Macmillan Ltd 0197-5897/07 \$30.00 www.palgrave-journals.com/jphp 
practitioners, researchers, and policy makers. Similarly, strong nongovernmental civil organizations to promote public health are needed in all countries. Together these country associations, through WFPHA, can bring a unified, assertive voice to the world stage on behalf of policies and practices that promote the health of populations. WFPHA, for example, has been a major advocate for global tobacco control policies.

Guided by the vision "to lead the quest for a healthy global society," WFPHA seeks resources to advance all the goals of the new strategic plan (see below). One goal is to assist member organizations, especially those in less wealthy countries, develop and sustain a viable infrastructure for the public health workforce and for advocates within their countries. The Canadian Public Health Association, with funding from the Canadian government, has developed model programs for peer-to-peer association exchanges. These need to be replicated in more parts of the world.

WFPHA will convene the 12th World Congress in Istanbul, Turkey, on April 27-May 1, 2009, to foster the exchange of public health research and practice. In addition, all members of APHA, a WFPHA association member, can receive a discounted subscription to WFPHA's official publication - Journal of Public Health Policy.

It was a privilege to represent APHA in WFPHA's revitalization effort. I applaud the past and current work of many APHA members and the leadership of the International Section in advocating on global public health issues. Finally, I thank APHA staff - Dr. Georges Benjamin (a current member of the WFPHA executive committee), Dr. Barbara Hatcher (Secretary General), Charlene Bright, and Morgan Taylor - for their steadfast commitment in assisting WFPHA secure funds for planning and implementation activities. In this age of globalization and of growing inequities in the conditions that assure the health of populations, we need WFPHA to be a strong global public health organization and voice!

\section{Contact:}

Deborah Klein Walker, Ed.D.

President, APHA

8001 Street, NW

Washington, DC 20001-3710, USA

E-mail: debbie.walker@earthline.net 


\section{Special Reports}

WFPHA Strategic Plan 2007-2012

(Drafted in Bellagio, Italy May 4, 2007)

The World Federation of Public Health Association (WFPHA) is an international, nongovernmental, multi-professional, and civil society organization bringing together for professional exchange, collaboration, and action, all people interested and active in safeguarding and promoting the public's health. Founded in 1967, it is the only worldwide professional society representing and serving the broad field of public health, as distinct from single disciplines or occupations. National and regional public health associations, presently numbering over 70 , are the Federation's governing members. Regional associations of schools of public health also belong.

The present strategic plan, covering the five-year period 2007-2012, was developed in May 2007, in a participatory process at the Rockefeller Foundation Bellagio Study and Conference Center. It updates the Federation's vision, mission, goals, and strategies and serves as a road map for activities. The plan will be reviewed and updated annually.

\section{Vision:}

To lead the quest for a healthy global society.

\section{Mission:}

WFPHA is an international, nongovernmental, multi-professional, and civil society organization, dedicated to promoting and protecting global public health.

\section{Values:}

Right to Health: We hold that health is a fundamental human right and a public good.

Social Justice: We advocate for equity and nondiscrimination and the elimination of health disparities.

Diversity and Inclusion: We promote a global public health perspective that includes diverse social and cultural backgrounds, ethnicity, race, gender, sexual orientation, and disability.

Partnership: We use partnership as the basis for mutual learning and capacity building.

Ethical Conduct: We believe in the ethical practice of public health for individuals and populations. 
Goals:

Goal One: To develop and promote effective global policies to improve the health of populations.

Goal Two: To advance public health practice, education/training, and research.

Goal Three: To expand and strengthen internal and external partnerships.

Goal Four. To achieve and maintain an effective, efficient, and sustainable organization.

Goal Five: To support member associations in improving their infrastructure and organizational capacity.

Note: For each goal, strategies have been outlined, which will be refined in a extensive discussion process before publication.

\section{Contact:}

Dr. Barbara Hatcher

Secretary General

c/o APHA

8001 Street, NW

Washington, DC 20001-3710, USA

E-mail: barbara.hatcher@wfpha.org

\section{WFPHA Members Presented}

In this section, the profiles of WFPHA member organizations are presented with their publications, projects, and activities. The section is introduced in this issue by a report on the overall status of the membership.

\section{World Federation of Public Health Organizations}

Summary of the Annual Reports of the Member Associations In the first issue of the Federation's Pages in 2007, a template for more standardized reporting was published, and 19 out of 73 member associations sent reports:

Bangladesh, Burkina Faso, Canada, China, Colombia, Costa Rica, Finland, Germany, Iran, Japan, Macedonia, Mozambique, Norway, South Africa, Switzerland, Turkey, Uganda, United Kingdom, and United States of America. 
Membership:

Associations reported membership (range 30,000-80,000). Three associations did not report the number of members. Excluding the Chinese Preventive Medicine Association (CPMA) with 80,000 and the American Public Health Association (APHA) with 50,000 members, the average association size was 995 members. We estimate total membership of WFPHA to be approximately 200,000 .

Results of Work:

The template asks for publications, conferences, ongoing projects, and planned activities. Few reports followed this scheme, although some refer to their websites. We estimate that on average, 2-5 publications have been issued - journal articles, books, or newsletters. Many associations ran conferences and research and development projects, and more are planned. So that we may generate better statistics next year, we urge the member organizations to prepare reports following the provided template. The report of the Asociación Costarricense de Salud Pública (ACOSAP) of Costa Rica could serve as a model (see below).

Expectations and proposals:

Many comments refer to the necessity to secure, with the help of WFPHA, financial support. They mentioned "twinning" between rich and poor associations to obtain grants. Others urged WFPHA to initiate and support Public Health Associations in countries still without such organization.

A second group of comments concerns the development of communication and information in a global and timely dimension (e.g. a bi-monthly newsletter). Some Public Health Associations would like to see their standardized profile on the WFPHA website.

Finally the key resource of WFPHA, that is, multi-nationality should be used more intensively to develop together and to apply for Research \& Development projects.

The comments in the association reports confirm the results of a 21-question survey conducted early in 2007. Details are available from the Secretary General Dr. Barbara Hatcher (Barbara.hatcher@apha.org).

\section{Contact:}

Professor Dr. med. Ulrich Laaser

Faculty of Health Sciences

University of Bielefeld

POB 100131 
D-33501 Bielefeld

E-mail: ulrich.laaser@uni-bielefeld.de

\section{Annual Report of the Costa Rica Public Health Association}

(according to the template in Journal of Public Health Policy 28/1 (2007): 150) Period covered: 2005/2006

Full legal name of the Association including official abbreviation:

Asociación Costarricense de Salud Pública (ACOSAP)

Full contact details of the head office (including TEL, FAX, E-MAIL, URL: TELEFAX): Tel.: (506) 233-8063.

Internet: acosap@ racsa.co.cr; acosap@gmail.com; www.acosap.org

Full name and titles of president:

Eng. Federico Paredes, M.Sc.

Full name and titles of executive director/general secretary:

Marcela Garita González, B.A.

Membership (number at the end of the last year): 250

List of publications during the reporting period (full references including ISBN and ISSN) andList of conferences and public meetings during the reporting period (dates, locations, themes, and attendance):

1. Two round tables about public health issues ("Conversatorios de Salud Pública"):

1.1. Precandidates to the Presidency of the Republic, November 2005 (100 participants)

1.2. "Values on Health," fundaments of a doctoral dissertation, by Dr. Francisco Sánchez, February 2006 (50 participants)

2. Opening of the Annual Lecture "Dr. Ross - Dr. Marranghello" on Health, November 2006 (30 participants)

3. ACOSAP delegation to the 11th World Congress on Public Health, Rio de Janeiro, Brasil, seven members, August 21-25, 2006

4. Xth National Congress on Public Health, sponsored by ACOSAP with the cooperation of the University of Costa Rica (UCR), October 10-13, 2006 (130 participants)

5. Annual General Assembly of ACOSAP, Balmoral Hotel, San José (120 participants) Friday, December 15, 2006.

List of ongoing Research \& Development projects during the reporting period (topics, donors, names of principal investigators including their contact details especially e-mail): 
"Otorgamiento de Avales a proyectos y/o programas educativos de promocion de la salud, productos o alimentos"

List of activities prepared/planned for the next reporting period:

1. Five round tables during the year 2007 ("Conversatorios") in different locations.

2. Second Annual Lecture "Ross - Marranghello," September 2007, San José

3. Envisaged cooperation with the Nicaraguan P.H.A. in cooperation with the Canadian Public Health Association (CPHA)

4. Field survey in Port Limón (Caribbean Coast) to determine the current status of the health workforce, May 2007, financial cooperation: PAHO and CPHA-CIDA

5. Celebration of the 25th Anniversary of the creation of ACOSAP, December 2007

Expectations and proposals regarding the WFPHA:

Since ACOSAP is the coordinator of the Regional Liaison Center (RLC) for the Americas, we need to know what the substantial cooperation of the WFPHA is going to be, mostly in terms of economical support. It is very hard to develop this Project with our lack of resources. For instance, in the past, WFPHA used to finance the printing of the Regional Bulletin for the Americas. Now, we certainly can use the electronic format, but this also means to have a dynamic web page, that is, it is necessary to pay the web host, etc.

Additional comments: Although ACOSAP plans to start a joint project with CPHA in Nicaragua, we firmly suggest WFPHA to consider a similar strategy for the rest of the countries that do not have any P.H.A. as there are Guatemala, Honduras, El Salvador, and Belize. We can also include Panama in this group. The mediator for such an effort could be Salus America. The project itself may include meetings with nationals in the respective countries, workshops in Costa Rica to train colleagues from Central America, editing some materials (handbooks and tool kits), the organization of Central American Conferences on Public Health, Development and Poverty, or the Environment and Public Health.

\section{Secretary General's Column}

May has been a busy month for the WFPHA. In addition to its Annual Meeting, held most years in Geneva, Switzerland, the Federation held a 
strategic planning retreat for the second time in its 40-year history. The retreat, supported by the Rockefeller Foundation, was held at the Foundation's study and conference Center in Bellagio, Italy. The theme of the retreat was "Strengthening Public Health Associations across the Globe: Moving from Good to Great."

Members of the Federation's Executive Board and strategic planning Committee as well as a Past President, the World Health Organization (WHO) liaison, and the Secretary General deliberated for 4 full days. Nestled in the hills of Italy, the quiet and solitude proved the perfect environment for coming together to renew and refocus the organization. The Federation reached a historic turning point.

The retreat was organized using the "good to great" format developed by organizational development expert, Jim Collins and adapted to the social sectors. The commissioned paper on "Strengthening Public Health Associations" by thought leader, Dr. Ilona Kickbusch, provided a call for action: "The federation must exert global leadership to build public health capacity throughout the world and counter the increasing fragmentation of the global public health system." Finally, Dr. Gualtiero Ricciardi, challenged the group to consider the diversity and cultural traditions of the WFPHA. These calls for action clearly charge the Federation to remember the key principle of the 1978 Alma Ata Declaration, "Health for All."

With these challenges in mind, the deliberations were skillfully guided by Mr. Colin Rorrie, the Retreat Facilitator. For the first time, the strategic plan includes a statement of vision and values that set the tone for Federation activities. As we began our participation in the 60th World Health Assembly, we noted that the Federation's plan, like that of WHO, addressed fundamental global public health, strategic, and operational needs (see the WFPHA Strategic Plan 2007-2012 above under special reports).

At its Annual Meeting held May 13, 2007, the Executive Board invited other organizational representatives to join working groups on the identified strategic WFPHA goals. These "Goal Groups" will work over the next 6 months to finalize strategies and activities. The entire plan will be disseminated and vetted among all member associations and approved at the May 2008 Annual Meeting.

As Federico Paredes, Executive Board member and President of the Public Health Association in Costa Rica has stated "LET'S DO IT!" Let us have an exciting year! 


\section{Contact:}

Dr. Barbara Hatcher

Secretary General

c/o APHA

8001 Street, NW

Washington, DC 20001-3710, USA

E-mail: barbara.hatcher@wfpha.org

\section{WFPHA News \& Notes}

\section{WFPHA Continues Official Relations with WHO}

Washington, DC, USA, March 19, 2007 - The World Federation of Public Health Associations (WFPHA) today announced its continuing official relationship with the World Health Organization (WHO). The WHO Executive Board agreed to extend official relations with the WFPHA in its 120th session.

Barbara J. Hatcher, Ph.D., MPH, RN, secretary general of WFPHA, welcomed the announcement. "The federation is pleased about its continued status with WHO and hopes to consolidate its ties in areas that will help the Federation's efforts to strengthen the public health associations globally," Hatcher said.

Upon hearing the news, WFPHA President, S.M. Asib Nasim, M.D., Ph.D., MPH., called on public health associations to continue to work together for their common interests. "The public health associations around the world need to come forward," Nasim said. "We need leaders who can call for action. This is the moment where we can stand up and say we can change the world. We need to encourage public health professionals and leaders around the globe to nurture their gained knowledge and build a sustainable world for future generations."

WHO Liaison to the WFPHA, Alena Petrakova, M.D., noted, "Professional public health associations at global, regional and local levels are collaborating with the WHO to find new ways to strengthen public health's role and workforce. They are seeking to provide leadership and innovation in applying developments in knowledge management, information and communications technology to serve health, particularly in those countries with critical shortages of health service providers."

One of the many collaborative efforts between the WHO and WFPHA is the Knowledge Management for Public Health (KM4PH) program. This partnership has entailed an informal consultation on the Global Network 
and Database for Public Health Partners, organized by KMS/WHO on December 7-8, 2005, which proposed a strategy to create a global network. The WHO Global Knowledge Management team supports this network in partnership with the WFPHA, Public Health Schools, and Institutes. This proposal was further developed by the KM4PH Core Advisory Group and discussed with the WFPHA during its Executive Board meetings in June and August 2006, as well as at the 40th Annual Meeting of the WFPHA on August 20, 2006 in Rio de Janeiro, Brazil. It was accepted as an integral part of the WFPHA strategic plan. WFPHA maintains close ties with UNICEF and other international organizations. More information is available at http://www.wfpha.org/.

\section{Contact:}

Alena PETRAKOVA, M.D., Ph.D.

$\mathrm{KM} 4 \mathrm{PH}$ Project Manager

Knowledge Management and Sharing

World Health Organization, Geneva, Switzerland

E-mail: petrakovaa@who.int

\section{Intervention Concerning Workers' Health: A Global Plan of Action}

Agenda Item 12.13, 60th World Health Assembly, May 2007

Barbara Hatcher, RN, PhD, MPH

Secretary General

World Federation of Public Health Associations

Thank you for the opportunity to speak in support of this important resolution on a Global Plan of Action for Workers' Health. My name is Barbara Hatcher. I am the Secretary General World Federation of Public Health Associations, an NGO representing public health professionals in 70 associations from 65 countries. Founded in 1967, WFPHA is a professional society representing and serving the broad field of public health, as distinct from single disciplines or occupations. WFPHA enjoys official relations status with the World Health Organization (WHO).

As public health professionals we are concerned, as WHO has documented, that a substantial proportion of the global burden of disease is caused by the conditions of work throughout the world. During this past year we have joined with the International Trade Union Confederation (ITUC), which represents 304 affiliated member organizations in 153 
countries and territories, with a total membership of 168 million workers, and the International Commission of Occupational Health $(\mathrm{ICOH})$, an international scientific society in the field of occupational health with a membership of over 2,000 professionals from 93 countries, to support the WHO Executive Board's proposal that the 60th World Health Assembly adopt an action plan for workers' health.

Our three organizations support the plan because it establishes a realistic long-term program to deal with specific issues of the work place, such as occupational cancer, chemicals, asbestos and heavy metal contamination, along with HIV AIDS. We are particularly enthusiastic about the collaboration projected by this proposal with the International Labor Organization (ILO) and with ministries of Labor and Health at the national level.

We feel that the Plan of Action allows for attention to these important elements:

(a) Cancer, through its references on occupational diseases, workplace hazards, and radiation

(b) Standards and Enforcement issues by its reference to strengthening WHO collaboration, protection, and chemical safety, as well as joint actions with the ILO, in dialogue with Labor ministries, and by seeking to adopt a basic set of occupational health standards and strengthening enforcement systems,

(c) Asbestos, by including a global campaign and national approaches for the elimination of asbestos-related diseases,

(d) HIV/AIDS, by agreeing to prevent and control the disease at the workplace,

(e) Cross-cutting issues, by recognizing the centrality of employment, sustainable development, poverty reduction, and environmental protection,

(f) Workers, by making them a focus of training and for consultation on capacity-building exercises, communication and awareness raising, and implementation of the Action Plan, which also includes a special focus on healthcare workers,

(g) Trade Unions, by including worker and employer representatives in the planning and implementation for reducing inequalities in workers' health, and in developing strategic tools for communication and awareness raising,

(h) Health Professional, by identifying concrete roles and responsibilities, and 
(i) Occupational health services by offering access to appropriate services for all working people of the world.

Our organizations pledge to participate in the implementation of this action plan and foster collaboration among ourselves, all civil society stakeholders, and WHO/ILO, in conjunction with the WHO network of Collaborating Centers in Occupational Health.

Editor's Note: On the 22nd of May 2007 the Committee A of the World Health Assembly endorsed the Resolution on the Global Plan of Action on Workers Health and today, the 23rd of May, the Global Plan of Action was officially adopted by the World Health Assembly!

\section{Implementing the RIO DECLARATION}

Brazilian Experience 2006-2007

Since our Congress in Rio de Janeiro in August 2006, ABRASCO has been working and promoting actions inspired by the Rio Declaration (published in Journal of Public Health Policy 27/4 (2006): 451-452), according to, and limited by, our existing agendas and interactions with our partners. There are three dimensions of our work:

(1) Supporting and cooperating in the development of the Working Plan of the Brazilian Committee on Social Determinants of Health (BCSDH) http://www.determinantes.fiocruz.br

The BCSDH working plan 2006-2009 has five areas of action: (i) knowledge production and dissemination; (ii) supporting and promoting programs and policies; monitoring and evaluating; (iii) promoting social participation; (iv) developing communication strategies; (v) international cooperation with the International Commission on Social Determinants of Health (WHO/PAHO) especially in the Latin American Region.

Within the BCSDH plan, by 2007, in the area the knowledge production and dissemination, 4 million dollars had been applied on selected researches to assess inequities in the access to health services and technologies, groups' vulnerability, human rights, ethics, race and ethnicity, environmental issues vis-à-vis the BCSDH principles and working frame.

(2) Heading the process of planning and organizing the IV Brazilian Congress on Social Science and Health in Salvador, July 15-18, 2007. 
This congress is an international initiative together with the Latin American Association on Social Medicine (ALAMES) and the International Association on Health Policy (IAHP). The main theme of these international congresses is "Equity, Ethics and Right to Health: Challenges in a Globalized World" http://www.congressosalvador2007. com.br/ingles/index.php

(3) Supporting the process of planning and organizing, together with the National Health Counsel the 13th National Health Conference - 49 counselors, including members from CONASS, CONASEMS, MOH, and representatives and leaders of Social Movements.

This ongoing process is beginning with districts, municipalities (more than five thousand municipalities), states (26 states and the Federal District), and ends with the National Health Conference, in the FD-Brasilia, from November 15-17, 2007.

In this National Health Conference, thousands of delegates, elected at municipality level, have a role in presenting their needs and to discuss and to defend the proposals.

The main theme selected at the beginning of 2007 is "Health and Quality of Life: State Policies and Development" as well as three subthemes: (i) Challenges for Health Rights in the XXI Century: State, Society and Development Patterns; (ii) Public Policies for Health and Quality of Life: the National Health System in the Social Security System and the Social Contract for Health; and (iii) Social Control and the Health Rights. www.conselho.saude.gov.br

\section{Contact:}

Álvaro Matida

Secretário Executivo da Abrasco

R. Leopoldo Bulhões, 1480, sl.208

Manguinhos - Rio de Janeiro - RJ

www.abrasco.org.br

E-mail: almatida@ensp.fiocruz.br 